\title{
Health of Left-behind Children in China: Evidence from Mediation Analysis
}

\author{
Yao Lu, Department of Sociology, Columbia University
}

Wei-Jun Jean Yeung, Department of Sociology, National University of Singapore

Jingming Liu, Department of Sociology, Tsinghua University, China

Donald J. Treiman, Department of Sociology, University of California, Los Angeles

\section{Full citations:}

Lu, Yao, Jean Wei-Jun Yeung, Jingming Liu, and Donald J. Treiman. 2019. "Health of Leftbehind Children in China: Evidence from Mediation Analysis." Chinese Journal of Sociology 5(4):431-452.

\section{Corresponding author:}

Yao Lu

Department of Sociology

Columbia University

New York, NY 10027, USA

yao.lu@columbia.edu

\section{Acknowledgement:}

The authors gratefully acknowledge support from the National Science Foundation (SES1027048), the National Institute of Child Health and Development (1K01HD073318), the Chiang Ching-Kuo foundation, the Columbia Population Research Center with funding from the National Institute of Child Health and Human Development (P2CHD058486), the Lippo Limited and Asia Research Institute at National University of Singapore, the National Social Science Fund of China (10ASH002), and the California Center for Population Research with funding from the National Institute of Child Health and Human Development (R24HD041022). The authors are grateful to the Tsinghua China Data Center, which conducted the "Urbanization and Labor Migration Survey" and the "Urbanization and Child Development Study". The authors also thank Irwin Garfinkel for valuable suggestions and Xiaoyu Zhang and Xuejiao Chen for excellent research assistance. 


\title{
Health of left-behind children in China: Evidence from mediation analysis
}

\begin{abstract}
Internal migration in China has resulted in large numbers of left-behind children. Despite growing attention to this population, existing research has not systematically addressed the mediating mechanisms linking parental migration to children's health. The present study examines the influences of migration on the health of left-behind children in China and the mediating channels, using data from a new nationally representative survey. We compare three groups of rural children ages 3-15 $(N=2,473)$ : those who were left behind by both parents, those who were left behind by one parent, and those living with both nonmigrant parents. Results show that the health of rural children left behind by both parents (but not by one parent) is worse than the health of children living with both parents. The health disadvantage of these children is mediated by their caregivers' poor health status and caregiving practices. These mediating factors not only have a direct impact on child health but also exert an indirect impact by shaping children's nutritional intake. Contrary to conventional wisdom, monetary remittances are not a significant mechanism linking migration to child health.
\end{abstract}

Keywords: Migration; Left-behind Children; Health 


\section{Introduction}

Migration processes have altered the state of the family in many societies. A sizeable fraction of children have experienced parental migration during their childhoods, either accompanying their parents or, more often, being left behind by them in order to mitigate the costs and uncertainty of migration. China represents a prominent example, where more than 168 million rural people have left their villages to seek work in cities (National Bureau of Statistics of China, 2016). As a result, an estimated 61 million Chinese children under age 18 ( $22 \%$ of all Chinese children and $38 \%$ of all rural children) have been left behind by one or both parents (All China Women's Federation [ACWF], 2013; Duan et al., 2013). Almost half of these children lived with neither of their parents. The high rate of left-behind children results from structural barriers in cities that preclude rural migrants from acquiring full citizenship and impose substantial difficulties in accessing social welfare (Chan and Buckingham, 2008). Hence, more migrants have left their children in rural areas than brought them to cities (ACWF, 2013). By some estimates, $80 \%$ of migrant workers have left their children behind (Zhao et al., 2014).

In the present study, we examine the health of left-behind children. We contend that parental migration is likely to have important implications for child health because it shapes both material and non-material resources in the family. Family economic and care input both contribute to children's healthy development by shaping children's nutrition intakes and exposure to morbidity. More available and better quality child care, as well as greater material resources, can improve nutrition, sanitation, and health care while protecting children from contamination and other health risk factors (Case et al., 2002; Currie, 2009).

Migration typically brings considerable economic improvement in household economics that can have a positive effect on health, but at the same time may adversely affect children by separating them from their parents and reducing the quantity and quality of the care they receive. On the one hand, households left behind typically benefit from migrants' economic contributions through remittances (Lopez, 2015; World Bank, 2016). These resources serve as a critical means of enhancing household 
living standards and providing a healthy home environment (Semyonov and Gorodzeisky, 2008). They allow for more resources to be allocated to health-related expenses that improve the quality and quantity of food, household sanitation, and use of health care services (Antón, 2010; Graham and Jordan, 2011). In this respect, parental migration is conducive to child health.

On the other hand, parental migration disrupts family practices and impairs parents' ability to care for their children. When children are left behind, they inevitably experience reduced parental input essential for their development (Dreby, 2010; Graham and Jordan, 2011; Hoang and Yeoh, 2012; Parreñas, 2005; Toyota et al., 2007). Concomitantly, remaining caregivers not only experience additional household responsibilities such as childcare, home maintenance, and agricultural production, but also endure emotional burdens because of separation from their loved ones, usually their spouse or adult children (Lu, 2012). These physical and psychological burdens subject the remaining caregivers to heightened health risks and stress, which may compound existing ailments (especially when elderly grandparents are the caregivers). Faced with these challenges, remaining caregivers tend to provide lower levels and standards of care and support to children (Smeekens et al., 2012) which, in extreme cases, may amount to child neglect (Zhong et al., 2012). Particularly relevant for children's health, the remaining caregivers tend to have limited ability to prepare nutritious food, to carry out sanitary care practices (e.g., clean children, keep the house clean), and to use health services to boost child health (e.g., immunizations, visits to health facilities) (Hildebrandt et al., 2005). In this respect, parental migration can be detrimental to the health of left-behind children.

Importantly, the reduced quantity and quality of care can undermine the potential positive economic effect of parental migration. The beneficial economic impact is premised on effective utilization of material resources for children. However, care deficits make it difficult to fully realize potential gains from improved household economies. Caregivers may be overwhelmed with household survival needs. They tend to direct their energies and resources to basic household maintenance rather than to improving children's well-being (Hildebrandt et al., 2005). The overworked caregivers may often be unable to spend sufficient time preparing nutritious meals or ensure that children ingest adequate nutrients and calories. 
Instead, they may substitute easy-to-prepare foods and unhealthy snacks for well-balanced and nutritious (but preparation-intensive) meals (Chang et al., 2019). This tendency may be exacerbated by inferior educational levels of substitute caregivers, who are often grandparents. The limited education of alternative caregivers may result in low health literacy and failure to adopt new parenting and health information (Graham and Jordan, 2011; Tan et al., 2010). The result is to further shift caregivers' attention and household resources away from investment in child well-being.

The social and economic mechanisms just discussed tend to vary by which parent migrates. Children are likely to be most adversely affected when they are left behind by both parents compared to when only one parent migrates. Caregiving practices are most severely disrupted when neither parent is available to continue their role as caregiver, . In this scenario, children are cared for either by their grandparents or by other relatives, who provide lower quality care and are less invested in children's well-being than parents are (Haveman and Wolfe, 1995). Previous work demonstrates that care from extended families is unable to replace parental care (de Brauw and $\mathrm{Mu}, 2011$ ). For this reason, in our analysis we distinguish between children left behind by one parent and children left behind by both parents.

Children of China's tidal wave of migrants present a looming challenge to societal development. The issue has generated much interest and debate over the impact of parental migration on the health and wellbeing of left-behind children in China. A key question is whether migrant parents' financial contributions outweigh the disruptions in care caused by their absence. Previous research provides mixed evidence on the health of Chinese left-behind children, regardless of whether health is measured by general health status, physical growth, or specific health problems. Some studies find left-behind children to have worse health than rural children who live with both parents (Gao et al., 2010; Hipgrave et al., 2014; Lei et al., 2018; Li et al., 2015; Murphy et al., 2016; Wen and Lin, 2012). Other studies, in contrast, suggest that left-behind children do not differ significantly in health from other rural children (Guo et al., 2017; Huang, et al., 2016; Lu et al., 2016; Tian et al., 2017; Xu and Xie, 2015; Zhou et al., 2015), or may even fare better (Mu and de Brauw, 2015). 
Several important gaps remain in our understanding of the health of left-behind children. Previous research has largely been based on local surveys, which limits the generalizability of findings. Also, earlier work has centered on children's health outcomes and has not systematically examined mediating mechanisms linking parental migration to child health. We are thus left with the question of how parental migration may affect the health of left-behind children. Investigating the underlying mechanisms is especially crucial given the offsetting pathways discussed above. For example, to what extent do disrupted caregiving practices as a result of migration affect the health of left-behind children? Do migrants' financial remittances promote children's health, or are the potential economic benefits offset by care deficits?

The present study examines these questions using data from a nationally representative sample survey we collected in 2012-2013 in China. We compare two groups of rural left-behind children (those left behind by one parent and those left behind by both parents) with rural children in non-migrant families. We specifically model possible beneficial and detrimental mechanisms that may link parental migration to child health, taking advantage of the rich information available on theoretically meaningful mediating factors. These factors include financial remittances and the characteristics and practices of children's primary caregivers. The receipt of remittances may improve household standards of living, including better food intake, which in turn boosts children's health. The behavior and characteristics of the primary caregiver tend to be shaped by migration and may subsequently affect the home environment and child well-being. Parental migration is often associated with reduced quality and quantity of caregiving. These care deficits can result in a less supportive home environment, leaving children with unmet developmental needs. In addition, migration of key household members can inflict considerable stress for remaining caregivers, thereby impairing their health and their ability to provide nurturing care. The mediating role of these factors is jointly assessed in the paper. 


\section{Data and Methods}

\section{Data}

Data are from a national probability sample survey, which was designed specifically to understand the effect of migration on children in China (Lu et al., 2019). The Survey, The Urbanization and Child Development Study, was the child component of the Urbanization and Labor Migration Survey conducted by Tsinghua University during 2012 and 2013 . The survey covered 500 villages and neighborhoods in 28 provinces across the nation (in common with almost all national samples in China these days, our sample omits a few sparsely populated provinces--Hainan, Qinghai, and Tibet--which together include less than $1.25 \%$ of the population). The survey was based on a multi-stage stratified national probability sample of Chinese households, with an oversample of townships with high rates of in-migration and out-migration. The sample design was intended to ensure a sample containing a sufficient number of children affected by migration (migrant children and left-behind children). In the fieldwork, small area mapping and listing was used to select households within each sampled community. This strategy has been increasingly adopted in national surveys in China.

The survey resulted in good national representation. As shown in Appendix A, the age, sex, and region distribution of our sampled children is similar to that from the 2010 census. Note that we show the weighted distribution. A weight was constructed to adjust for the over-sampling of high out-migration and high in-migration areas.

The survey collected data on 6,796 children aged $0-15$, among which 3,542 were living in rural areas at the time of the survey. A rich set of information was gathered from children's primary caregivers (PCGs), defined as those primarily responsible for taking care of the child. This information includes family socioeconomic status, PCG's parenting practices, PCG's well-being, and a range of child outcomes (education, cognitive, health, and psychosocial). The questionnaires and instruments were 
initially prepared in English, then translated into Chinese, and back-translated to ensure accuracy. They were also pre-tested before field implementation.

We restricted our analysis to rural children aged 3-15 living in rural areas (2,684 children) because infants and toddlers tend to have different health trajectories (Howard et al., 2011) and are less likely to be left behind by both parents. We distinguished between rural children living with non-migrant parents and rural children left behind by one or both migrant parents. Because our study focuses on children affected by migration, we excluded a small proportion of children in other types of non-intact families resulting from divorce or the death of a parent. Also, we focused on cross-county migration for reasons discussed below and dropped children whose parents migrated within the county. The final analytic sample size was 2,473 .

\section{Variables}

The key outcome variable is PCG-rated child health, a measure commonly used in studies of children (Flaherty et al., 2006; Reinbold, 2017). The measure takes different components of health into account and thus captures children's global health status (Krause and Jay, 1994). Existing research shows that guardians generally have a good sense of children's health. Their reports are highly correlated with objective health indicators and relatively accurately predict subsequent morbidity and mortality (Ferraro and Farmer, 1999; Runyan, 2001). In our survey, the PCGs were asked: 'In general, would you say that [child] 's health is excellent, very good, good, fair, or poor?' We treated the measure as a linear variable in the analysis to capture subtle changes across the entire spectrum of health status categories. The variable was coded such that higher values indicated better health. We conducted additional analyses, including dichotomous dependent variables, with excellent or very good health coded as 1 (and 0 otherwise), and obtained similar results. 
The key predictor is the parental migration status of rural children (those with local rural registration [hukou]): children living with both parents; left-behind children whose father or mother was a migrant; and left-behind children whose father and mother were both migrants. Specifically, left-behind children were defined as those whose parent(s) had migrated outside the county for work and were living outside the county at the time of the interview. We focused on cross-county migration, following the standard definition in China (ACWF, 2013). This is because within-county (e.g., cross-village or cross-township) migration involves shorter distances and more limited change in the socioeconomic environment than longer-distance migration. Parents who migrate within the same county often commute daily or regularly, which is different from the typical left-behind situation in which parents spend most of their time away from children. Our primary focus is on children left behind by both parents because, as shown later, the negative effects on health are restricted to this group of children.

We examine several mediating variables that potentially explain differences in child health by parental migration status. First, the amount of remittances in RMB (Chinese currency) is a continuous variable indicating how much the migrant parent has remitted in the past year. In 2012-2013, the value of the RMB was about $\$ 0.16$. If the household received remittances from both parents, the total amount was used. This variable was coded 0 for children in non-migrant families. We then log-transformed this variable, adding a small value to zeros (RMB 0.5 yuan) to retain such cases. We carried out additional analyses using a dichotomous variable — whether the child's household received any remittances. The results of the two sets of analyses are consistent.

Second, PCG's parenting practices are assessed using a scale comprised of a series of questions adapted from Child Trends and PSID-CDS (Hofferth et al., 1997). The scale taps parental involvement and parent-child interaction in the last month. We used it to proxy the quality and quantity of care provided by the caregivers. Questions include how often the PCG talked to the child and played with the child. Responses initially were coded on a five-point scale where 1 indicates 'Not in the past month' and 5 indicates 'Every day'. However, to facilitate discussion of the results, we reversed the coding so that 
higher values indicate less attentive parenting. The items were first standardized and then averaged to create the scale. The Chronbach's alpha is 0.86 , suggesting relatively high reliability of the measure. Ideally, we would have liked to assess other caregiving practices such as routine care (feeding, bathing, etc.). But such information was not available in the data.

Third, PCG's health is a continuous variable derived from a question about self-rated health (with similar wording and categories to the health question PGCs were asked about children). The variable was coded such that higher values indicated worse health (which reversed our coding of the child's health measure for ease of interpretation of mediating results).

Lastly, we included children's protein intake as a more proximate mediator with which to examine how various economic and social changes resulting from parental migration shape children's nutrition intakes and thereby their health. This analysis offers insight into the degree to which the potential positive and negative consequences of parental migration affect factors most closely associated with child health. We used protein intake to proxy nutrition intake because protein provides essential nutrients that boost children's growth and health (Müller and Krawinkel, 2005). By contrast, insufficient intake of protein increases children's susceptibility to illness and delays growth. The survey does not provide information on detailed calorie intake. In the survey, we asked how often children ate meat, seafood, or dairy products in the past week (none, 1-2 times, 3-5 times, 6-7 times or more), which constitute the primary sources of quality protein (Morgan et al., 2004). We first standardized the items and then averaged them to create a linear scale. Standardization was done for the entire child sample. Details of all mediators are shown in Appendix B.

Control variables included child's sex and age, number of siblings present at home, whether the child was a member of an ethnic minority, the PCG's sex and highest level of education (less than middle school, middle school, or high school and above), per capita family income (logged, not including remittances), and region of residence. We included both linear and quadratic age terms to capture possible nonlinear health difference by age. The number of siblings, as well as the sex and education of the PCG, 
are likely to affect caregiving practices and intra-household resource allocation (Zang and Zhao, 2017). Family income is known to strongly predict multiple domains of child development, including health (Goode et al., 2014). We included region of current residence to account for possible regional differences in both parental migration status and child health (e.g., children in less developed regions may both be more likely to be left behind and have poorer health). Including region also allowed us to assess underexplored regional variation in children's health. We categorized region by a conventional fourregion classification (North and Northeast, East, South-Central, and West), according to the State Council Development Research Centre (2002).

\section{Methods}

We estimated the overall impact and mediating mechanisms through multiple mediator models with parallel serial paths (Hayes, 2017). The models are estimated under a structural equation modeling framework. They simultaneously estimate the direct effect of parental migration on child health and the indirect effects through various mediators, while allowing for some mediators to influence other (more proximate) mediators. We used bootstrapping algorithms in the estimation, which relax many of the assumptions in ordinary inferential statistics and generate greater statistical power (Hayes, 2017; Williams and MacKinnon, 2008). Mediation analysis with bootstrapping is a valid and powerful method for testing intervening variable effects. We used complete cases in the analysis (dropping $4 \%$ of cases with missing data on any variable included in the analysis). The analysis was conducted in Mplus (version 7.4). We present standardized coefficients in the results section.

\section{Results}

\section{Descriptive Statistics}

Table 1 shows descriptive statistics for the variables used in the analysis. Among 2,473 rural children, $16.8 \%(416)$ were left behind by both parents. Another $14.2 \%(352)$ were left behind by either a migrant 
father or a migrant mother. The percentage of children with migrant mothers only was low, at $2.2 \%$, indicating that most children left behind by one parent are separated from their father. These results are consistent with earlier work showing that a little over half of all left-behind children had no parent at home (ACWF, 2013). In an additional analysis, we found that when both parents migrated, almost all children $(96 \%)$ were cared for by their grandparents. When children were left behind by one parent, the remaining parent usually took on the primary caregiving role.

[Table 1 about here]

Descriptive statistics are presented separately by children's migration status. We see that left-behind children had worse health than children in non-migrant families. This was particularly true for children left behind by both parents. The PCGs of left-behind children were less healthy and less attentive, especially when both parents of children migrated. This suggests that parents tend to adopt more positive parenting practices than alternative caregivers. By definition, households of children left behind received more remittances (since we coded remittances to be 0.5 for all children living with both parents and the $\log$ of 0.5 is -0.69). More interestingly, households of children left behind with one parent received more remittances than households of children left behind by both parents, presumably reflecting other differences in the two types of households. Protein intake was extremely low for rural children, as indicated by the negative average standardized score. Left-behind children suffered from even lower intakes compared to rural non-migrant children.

As for covariates, children left behind by both parents were slightly younger and more likely to be male than rural non-migrant children. The PCGs for left-behind children were more likely to be female and less educated (especially when both parents migrated). This reflects the fact that when both parents migrated, grandparents often became the PCGs of left-behind children. Children left behind by one parent had more siblings. This is perhaps because having more children increases the likelihood that at least one parent would stay behind to take care of the children. Minority children were slightly less likely to be left behind than Han rural children. There was some regional variation in the distribution of children. Left- 
behind children were concentrated disproportionately in the less developed West and South-Central regions.

\section{Results of Mediation Analyses}

Results from mediation analysis are displayed in Table 2 and Figure 1. The total effect of being left behind by both parents is negative and significant (left panel). The model RMSEA (Root Mean Square Error of Approximation) is 0.01 and the CFI (comparative fit index) is 1 . Both of these common model fit indices indicate a good model fit (RMSEA below 0.05 and CFI above 0.9) (Kline, 2005). This suggests that rural children left behind by both parents were worse off in health than were rural non-migrant children. In contrast, there was little overall difference in health between children left behind by one parent and rural non-migrant children (right panel). The coefficient for the effect of being left by one parent is -0.01 with a standard error of 0.02 (insignificant). For this reason, the mediation analysis focuses on rural children left behind by both parents.

[Table 2 about here]

The total indirect effect for children left behind by both parents was also negative and significant. These results show that the health vulnerabilities of children left behind by both parents are mostly explained through PCG parenting practices and PCG health. The patterns are more clearly illustrated in Figure 1. Specifically, parental migration is associated with less attentive parenting and poorer PCG health, which in turn adversely affects child health. The estimated indirect effect of parental migration on child health through PCG practices is -0.01 . This means that about $17 \%$ of left-behind children's health disadvantage (-0.01 out of -0.06) is accounted for by the negative effect of parental migration on PCG involvement, which in turn lowers health. The estimated indirect effect of parental migration through PCG health was even greater in magnitude, underscoring the physical constraints of grandparents in providing adequate care to children. 
[Figure 1 about here]

Protein intake is also an important mediating factor that is positively associated with child health. It provides another channel through which PCG practices and well-being affect child health. Specifically, less attentive parenting and poorer PCG health not only directly and adversely affect children's health, but also reduce children's protein intake, which subsequently compromises child health. Taken together, much of the disadvantage faced by children left behind by both parents is due to the fact that, compared with rural non-migrant children, their PCGs are less healthy and less likely to provide adequate care, both of which negatively affect children's health and also lead to lower protein intake which, in turn, reduces children's health.

Independent of these two mechanisms, remittances did not significantly mediate the effect of parental migration on child health. Being left behind was associated with greater financial remittances. Nevertheless, these remittances do not seem to have improved children's nutrition intake nor did they have a significant direct effect on health (net of nutrition). Although the coefficient of remittances on protein intake is negative and significant, the test for this mediating channel is insignificant (Table 2). This is due to the greater power of the joint test of the two paths than the power of the test of their product (MacKinnon, 2008). This result suggests that improved material resources from remittances are not necessarily directed at improving nutrition or other expenditures that can boost children's health. Hence, monetary remittances do not offset the negative social consequences of parental migration, leading to an overall negative impact of parental migration on health.

Beyond the mediating mechanisms specifically examined in our analysis, there was no significant direct effect of migration. The full mediating model is in Table 3.

With respect to other covariates, we see that children's health improved with age and PCG's education. Higher family income per capita was also associated with better health. Finally, region of residence was associated with children's health. Children in Northern China enjoyed the best health, followed by children in the East, West, and South-Central China. 
[Table 3 about here]

For children left behind by one parent (right panel, Table 2), the total effect of being left behind was nonsignificant. This could be due to the countervailing effects of care deficits and economic remittances. As a result, the total indirect effect for children left behind by one parent was nonsignificant. Specifically, the negative impact is channeled mainly through the PCG's poorer health, but not poorer caregiving practices. This is expected because one parent (mostly the mother) remains with the children. In the meantime, the positive economic impact of parental migration is realized when only one parent (usually the father) goes out to work. In these families, the remaining parent seems to be better able to invest in children's development in ways that enhance health (though not specifically through improving protein intake).

\section{Discussion and Conclusion}

The present study examines child health in the context of massive rural-to-urban migration in China. It extends existing research on the effect of migration on children's development by using a recent, nationally representative survey and investigating mediating mechanisms. This enables us to understand not only whether left-behind children fare differently in health from non-migrant children but also why they do so.

The results show that children left behind by both parents experienced the most health deficits. Children left behind by one parent (usually the father) did not fare significantly differently in health from children who lived with both parents. This is perhaps because the basic level of family unity is preserved, and improved economic resources offset the negative disruption effects of parental absence.

Much of the health disadvantage facing children left behind by both parents is mediated through the practices and health of children's primary caregivers. The experience of being left behind by both parents results in the lack of an attentive care environment and replaces the child's parents with caregivers who are more likely to have health challenges themselves. This generally deprives children of proper care and 
a healthy home environment. The care deficits also lead to lower nutrition intake, at least in the form of protein, which further compromises the health of left-behind children. Contrary to what is often expected, monetary remittances from two migrant parents do not seem to buffer the negative consequences of family disruption due to parental migration. Remittances do not have a direct impact on children's health, nor do they indirectly affect children's health by improving nutrition intake. Hence, when both parents are absent, children do not appear to benefit from their parents' economic contributions. This could be the result of resource allocation that channels improved economic resources away from expenditures on children. This is especially likely if increased income from remittances is used to save for future expenditures. Alternatively, it could reflect the time and energy constraints of remaining caregivers in investing in and being devoted to child development. Both processes likely strip children of the health gains that they could potentially have garnered from their parents' remittances.

Overall, this research highlights the role of migration in shaping child health, as it is closely linked to two key family factors influencing children, family monetary and social input. Children left behind are deprived of quality care and adequate investment, particularly when both of their parents go out for work. This presents left-behind children with substantial health challenges. The situation of the vast number of left-behind children in China is unsettling because more than half of them endure separation from both parents. It is also disheartening that parental migration has not given children left behind a developmental advantage as their parents clearly hoped — one of the primary reasons for migration is to enhance the life chances of their offspring through improved economic resources. This household strategy has not worked as expected. In some cases, parental out-migration even puts children at risk for unhealthy development.

Our study does not suggest that the PCGs of left-behind children are irresponsible or reluctant to care for and invest in their children. On the contrary, care deficits often arise because remaining caregivers assume too many household responsibilities as the only adult(s) in the household to monitor and support left-behind children. Many of the PCGs are elderly grandparents who themselves have health impairments and need care. They often must not only take care of left-behind children but also maintain the household 
and work in the fields. These burdens impose substantial time and energy constraints on the PCGs, putting them at high risk for health deterioration and compromising their ability to provide a healthy and supportive home environment for left-behind children.

For the foreseeable future, rural-to-urban migration will continue to be a reality in China. The plight of rural children growing up with neither parent presents major challenges to the society's social development. Further understanding the circumstances of left-behind children, including the mechanisms explaining their vulnerabilities and possible protective factors, is necessary for the design of programs targeting these children. When parent-child separation cannot be avoided, devising strategies that can mitigate the negative impact of parental migration on children is crucial. For example, we find that leftbehind children suffer largely because their non-parental guardians (mostly grandparents) often experience health challenges and are unable to provide an attentive care environment. These caregivers substitute for absent migrants in childcare and home maintenance but are themselves in need of care and support. Unfortunately, initiatives targeted at supporting these alternative caregivers have been very scarce. It is important that rural governments and communities recognize the key roles played by alternative caregivers and go beyond a solely child-centered approach to address problems facing leftbehind children. This means designing policies to provide caregivers with greater support and mobilizing resources to alleviate their burdens. It is also crucial that caregivers be provided with greater health literacy. This will allow them to make proper time and resource investments in health and nutrition to foster left-behind children's healthy development. Moreover, considering the low nutritional intake of rural children, providing nutritious meals and supplements in school-based settings is likely to offset the nutritional deficits that many children experience at home and improve the children's health in general.

Despite the merits of the survey data and the new insights we provide, a few limitations to our study warrant discussion. One limitation is that we do not measure other possible mediating mechanisms. Future studies should investigate potential positive paths that are underexplored in this paper, especially given a positive (though non-significant) direct effect that is independent of caregivers' characteristics 
and nutrition intake. Another limitation is that the data are cross-sectional, thereby hindering our ability to address potential endogeneity in the relationship between migration, PCG characteristics, and child health. For example, there may be factors that negatively affect both PCG's and children's well-being. This, however, is unlikely to be a major concern considering the positive health selectivity of migrants in China (Lu and Qin, 2014). To the extent that migrants themselves are healthier and there is a positive correlation between household members, children left behind are predisposed to have better health to begin with. This would suggest that our estimates are conservative and tend to underestimate the negative health impact of parental migration on children. In addition, it is possible that the onset of a serious health problem for a child may prompt one or both migrant parents to return home. This scenario is probably not a major concern. Very few rural children in our sample have poor health (less than $2 \%$ ). Also, even if a child's poor health prompts a migrant parent or parents to return, the child would be included in the migrant category at the time of the survey. The effect would be to underestimate the health disadvantage of left-behind children. That is, insofar as there is any reverse causality, the true negative effect of parental migration on child health would likely be more pronounced than our estimate shows. There is still more to be done on this topic. Longitudinal data with a richer set of potential mediating factors are needed to more definitively pin down the effect of migration on children and its underlying channels.

We have studied left-behind children in China, where the sheer magnitude and societal implications of migration are unprecedented. But the phenomenon is not unique to China. There has been substantial migration within and among many other nations. Many countries in Africa, Asia, and Latin America have experienced large-scale internal migration and international migration. It would be helpful to conduct studies in these settings that compare children in intact families with those left behind to assess the mechanisms we identify here—namely caregivers' well-being and practices, as well as remittances—in linking migration to children's health. Such studies would help policy-makers to devise policies that both minimize the costs and maximize the benefits of migration for children. 


\section{Funding}

The authors gratefully acknowledge support from the National Science Foundation (SES-1027048), the National Institute of Child Health and Development (1K01HD073318), the Columbia Population Research Center with funding from the National Institute of Child Health and Human Development (P2CHD058486), the Lippo Limited and Asia Research Institute at National University of Singapore, the National Social Science Fund of China (10ASH002), and the California Center for Population Research with funding from the National Institute of Child Health and Human Development (R24HD041022).

\section{Acknowledgement}

The authors are grateful to the Tsinghua China Data Center, which conducted the 'Urbanization and Labor Migration Survey' and the 'Urbanization and Child Development Study'. The authors also thank Irwin Garfinkel for valuable suggestions and Xiaoyu Zhang and Xuejiao Chen for excellent research assistance.

\section{References}

All China Women's Federation (2013) China's Rural Left-behind Children, Rural and Urban Migrant Children Research Report. Available at: http://acwf.people.com.cn/n/2013/0510/c9901321437965.html. (Accessed June 3, 2018)

Antón JI (2010) The impact of remittances on nutritional status of children in Ecuador. International Migration Review 44(2): 269-299.

Case A, Lubotsky D and Paxson C (2002) Economic status and health in childhood: The origins of the gradient. American Economic Review 92(5): 1308-1334.

Chan KW and Buckingham W (2008) Is China abolishing the hukou system? The China Quarterly 195: 
582-606.

Chang F, Shi Y, Shen A, Kohrman A, Li K, Wan Q, Kenny K and Rozelle S (2019) Understanding the situation of China's left-behind children: A mixed-methods analysis. The Developing Economies 57(1): 3-35.

Currie J (2009) Healthy, wealthy, and wise? socioeconomic status, poor health in childhood, and human capital development. Journal of Economic Literature 47(1): 87-122.

de Brauw A and Mu R (2011) Migration and the overweight and underweight status of children in rural China. Food Policy 36(1): 88-100.

Dreby J (2010) Divided by Borders: Mexican Migrants and Their Children. Berkeley, CA: University of California Press.

Duan CR, Lv LD and Zou XJ (2013) Major challenges for Chinas floating population and policy suggestions: An analysis of the 2010 population census data. Population Research and Policy Review 37: 17-24.

Ferraro KF and Farmer MM (1999) Utility of health data from social surveys: Is there a gold standard for measuring morbidity? American Sociological Review 64(2): 303-315.

Flaherty EG, Thompson R, Litrownik AJ, Theodore A, English DJ, Black MM, Wike T, Whimper L, Runyan DK and Dubowitz H (2006) Effect of early childhood adversity on child health. Archives of Pediatrics and Adolescent Medicine 160(12): 1232-1238.

Gao Y, Li LP, Kim JH, Congdon N, Lau J and Griffiths S (2010) The impact of parental migration on health status and health behaviours among left behind adolescent school children in China. $B M C$ Public Health 10(1): 56.

Goode A, Mavromaras K and Zhu R (2014) Family income and child health in China. China Economic Review 29: 152-165. 
Graham E and Jordan LP (2011) Migrant parents and the psychological well-being of left-behind children in Southeast Asia. Journal of Marriage and Family 73(4): 763-787.

Guo Q and Sun W and Wang Y (2017) Effect of parental migration on children's health in rural China. Review of Development Economic 21(4): 1132-1157.

Haveman R and Wolfe B (1995) The determinants of children's attainments: A review of methods and findings. Journal of Economic Literature 33(4): 1829-1878.

Hayes AF (2017) Introduction to Mediation, Moderation, and Conditional Process Analysis: A Regression-Based Approach, second ed. New York: Guilford Publications.

Hildebrandt N, McKenzie DJ, Esquivel G and Schargrodsky E (2005) The effect of migration on child health in Mexico. Economia 6(1): 257-289.

Hipgrave DB, Fu X, Zhou H, Jin Y, Wang X, Chang S, Scherpbier RW, Wang Y and Guo S (2014) Poor complementary feeding practices and high anemia prevalence among infants and young children in rural central and western China. European Journal of Clinical Nutrition 68(8): 916.

Hoang LA and Yeoh BS (2012) Sustaining families across transnational spaces: Vietnamese migrant parents and their left-behind children. Asian Studies Review 36(3): 307-327.

Hofferth S, Davis-Kean PE, Davis J and Finkelstein J (1997) The Child Development Supplement to the Panel Study of Income Dynamics: 1997 User Guide. Survey Research Center, Institute for Social Research, University of Michigan, Ann Arbor.

Howard K, Martin A, Berlin LJ and Brooks-Gunn J (2011) Early mother-child separation, parenting, and child well-being in early head start families. Attachment \& Human Development 13(1): 5-26.

Huang YQ, Song Q, Tao R and Liang Z (2016) Migration, family arrangement, and children's health in China. Child Development 89: e74-e90.

Kline RB (2005) Principles and Practice of Structural Equation Modeling, second ed. New York: The 
Guilford Press.

Krause NM and Jay GM (1994) What do global self-rated health items measure? Medical Care 32(9): 930-942.

Lei LL, Liu F and Hill E (2018) Labour migration and health of left-behind children in China. Journal of Development Studies 54 (1): 93-110.

Li Q, Liu G and Zang WB (2015) The health of left-behind children in rural China. China Economic Review 36(c): 367-376.

Lopez SL (2015) The Remittance Landscape: Spaces of Migration in Rural Mexico and Urban USA. Chicago: University of Chicago Press.

Lu S, Lin YT, Vikse JH and Huang CC (2016) Well-being of migrant and left-behind children in China: Education, health, parenting, and personal values. International Journal of Social Welfare 25(1): 5868.

Lu Y (2012) Household migration, social support, and psychosocial health: The perspective from migrant-sending areas. Social Science \& Medicine 74(2): 135-142.

Lu Y and Qin LJ (2014) Healthy migrant and salmon bias hypotheses: A study of health and internal migration in China. Social Science \& Medicine 102(C): 41-48.

Lu Y, Yeung JW, Liu JM and Treiman DJ (2019) Migration and children's psychosocial development in China: When and why migration matters. Social Science Research 77: 130-147.

MacKinnon WJ (2008) Introduction of Statistical Mediation Analysis. New York, NY: Routledge.

Morgan J, Taylor A and Fewtrell M (2004) Meat consumption is positively associated with psychomotor outcome in children up to 24 months of age. Journal of Pediatric Gastroenterology and Nutrition 39(5): 493-8.

Mu R and de Brauw A (2015) Migration and young child nutrition: Evidence from rural China. Journal of 
Population Economic 28(3): 631-657.

Müller O and Krawinkel M (2005) Malnutrition and health in developing countries. Canadian Medical Association Journal 173(3): 279-86.

Murphy R, Zhou MH and Tao R (2016) Parents migration and children's subjective well-being and health: Evidence from rural China. Population Space and Place 22(8): 766-780.

National Bureau of Statistics of China (2016) Statistical Communiqué of the Peoples Republic of China on the 2015 National Economic and Social Development. Available at: http://www.stats.gov.cn/english/pressrelease/201602/t20160229_1324019.html.

Parreñas R (2005) Children of Global Migration: Transnational Families and Gendered Woes. California: Stanford University Press.

Reinbold GW (2017) Exploring long-term economic well-being and child outcomes with the supplemental poverty measure: Evidence from the panel study of income dynamics. Journal of Children and Poverty 23(1): 1-17.

Runyan DK (2001) Monitoring child health and well-being in large population surveys. In: Thornton A (ed.) The Well-being of Children and Families: Research and Data Needs. Ann Arbor: University of Michigan Press, pp 85-103.

Semyonov M and Gorodzeisky A (2008) Labor migration, remittances and economic well-being of households in the Philippines. Population Research and Policy Review 27(5): 619.

Smeekens C, Stroebe MS and Abakoumkin G (2012) The impact of migratory separation from parents on the health of adolescents in the Philippines. Social Science \& Medicine 75(12): 2250-2257.

State Council Development Research Centre (2002) Analysis of the Features of Regional Social and Economic Development in China. Beijing: State Council Development Research Centre (in Chinese).

Tan C, Luo J, Zong R, Fu C, Zhang L, Mou J and Duan D (2010) Nutrition knowledge, attitudes, 
behaviours and the influencing factors among non-parent caregivers of rural left-behind children under 7 years old in China. Public Health Nutrition 13(10): 1663-1668.

Tian X, Ding C, Shen C and Wang H (2017) Does parental migration have negative impact on the growth of left-behind children?-New evidence from longitudinal data in rural China. International Journal of Environmental Research and Public Health 14(11): 1308.

Toyota M, Yeoh BSA and Nguyen L (2007) Bringing the 'left behind' back into view in Asia: A framework for understanding the 'migration-left behind nexus'. Population Space and Place 13(3): $157-161$.

Wen M and Lin D (2012) Child development in rural China: children left behind by their migrant parents and children of nonmigrant families. Child Development 83(1): 120-136.

Williams J and MacKinnon DP (2008) Resampling and distribution of the product methods for testing indirect effects in complex models. Structural Equation Modeling 15(1): 23-51.

World Bank (2016) Migration and Remittances Factbook 2016, Third ed. Washington DC: World Bank.

Xu H and Xie Y (2015) The causal effects of rural-to-urban migration on children's well-being in China. European Sociological Review 31(4): 502-519.

Zang XW and Zhao LX (2017) Handbook on the Family and Marriage in China. UK, Cheltenham: Edward Elgar Publishing.

Zhao QR, Yu XH, Wang XB and Glauben T (2014) The impact of parental migration on childrens school performance in rural China. China Economic Review 31: 43-54.

Zhong Y, Zhong ZH, Pan JP, Wang YX, Liu CY, Yang X, Hu C, Cai LL and Xu Y (2012) The situation of child neglect between left-behind children and living-with-parents children in rural areas of two Western provinces of China. Chinese Journal of Preventive Medicine 46(1): 38-41 (in Chinese).

Zhou C, Sylvia S, Zhang L, Luo R, Yi H, Liu C, Shi Y, Loyalka P, Chu J, Medina A and Rozelle S 
(2015) China's left-behind children: Impact of parental migration on health, nutrition, and educational outcomes. Health Affairs 34(11): 1964-1971. 

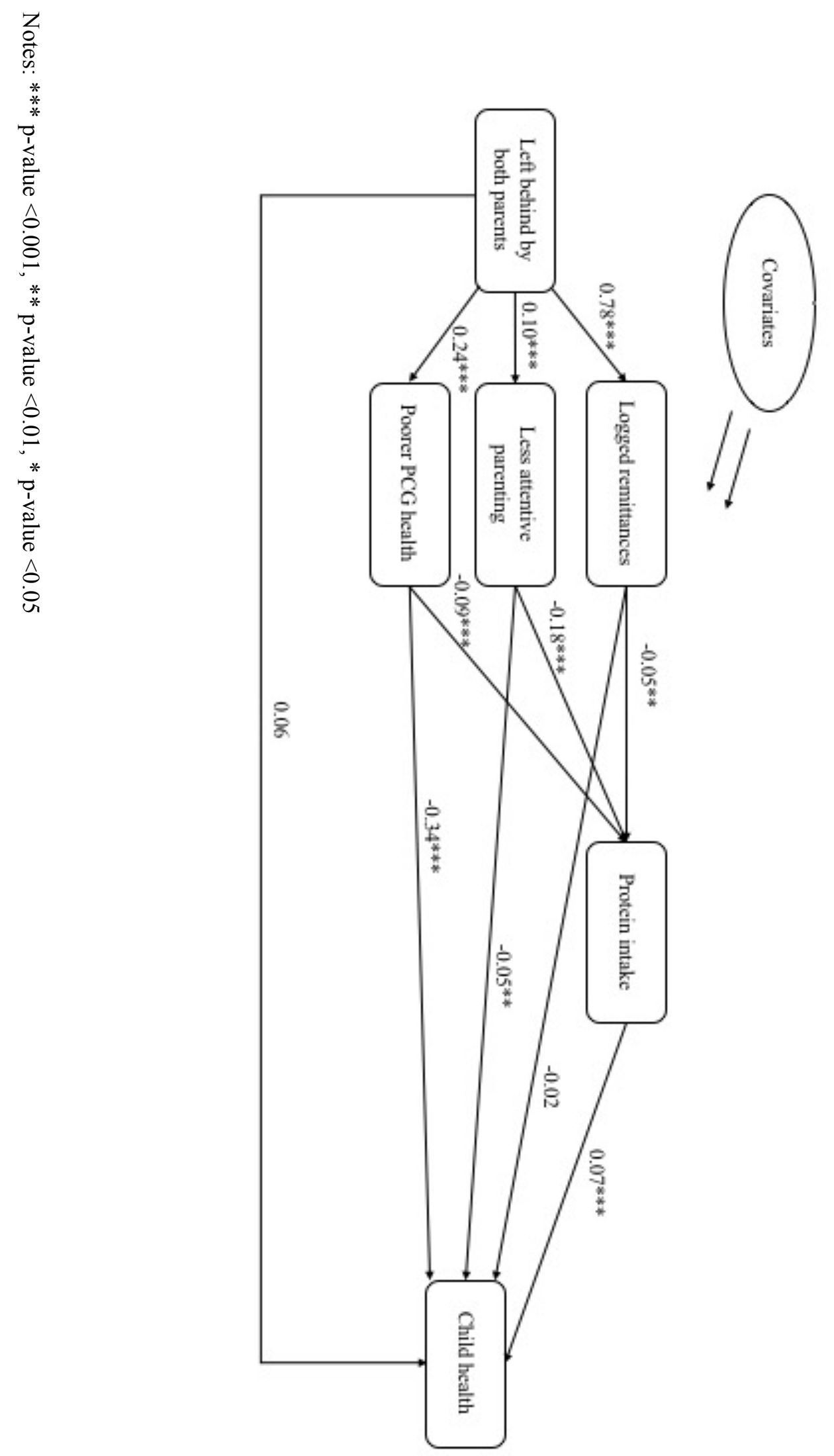

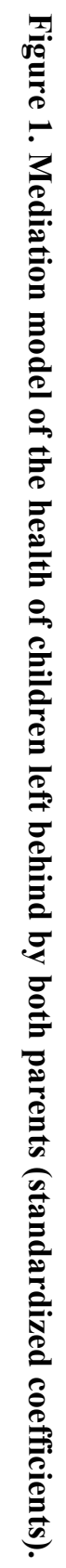


Table 1. Descriptive statistics.

\begin{tabular}{|c|c|c|c|c|}
\hline & $\begin{array}{l}\text { All rural } \\
\text { children }\end{array}$ & $\begin{array}{c}\text { Children living } \\
\text { with both parents }\end{array}$ & $\begin{array}{c}\text { Children left behind } \\
\text { by one parent }\end{array}$ & $\begin{array}{c}\text { Children left behind } \\
\text { by both parents }\end{array}$ \\
\hline \multicolumn{5}{|l|}{$D V$} \\
\hline Child health & $\begin{array}{c}3.44 \\
(0.93)\end{array}$ & $\begin{array}{l}3.49 \\
(0.91)\end{array}$ & $\begin{array}{l}3.38 \\
(0.96)\end{array}$ & $\begin{array}{l}3.29 \\
(0.94)\end{array}$ \\
\hline \multicolumn{5}{|l|}{ Mediators } \\
\hline PCG poor health & $\begin{array}{c}2.98 \\
(1.08)\end{array}$ & $\begin{array}{c}2.82 \\
(1.03)\end{array}$ & $\begin{array}{c}3.07 \\
(1.05)\end{array}$ & $\begin{array}{c}3.58 \\
(1.06)\end{array}$ \\
\hline PCG less attentive parenting & $\begin{array}{l}0.20 \\
(0.69)\end{array}$ & $\begin{array}{c}0.14 \\
(0.69)\end{array}$ & $\begin{array}{c}0.22 \\
(0.69)\end{array}$ & $\begin{array}{c}0.40 \\
(0.65)\end{array}$ \\
\hline Remittance (logged) & $\begin{array}{c}1.45 \\
(4.05)\end{array}$ & $\begin{array}{l}-0.69 \\
(0.00)\end{array}$ & $\begin{array}{c}6.65 \\
(4.50)\end{array}$ & $\begin{array}{c}5.84 \\
(4.46)\end{array}$ \\
\hline Protein intake & $\begin{array}{l}-0.19 \\
(0.74)\end{array}$ & $\begin{array}{l}-0.10 \\
(0.75)\end{array}$ & $\begin{array}{l}-0.48 \\
(0.67)\end{array}$ & $\begin{array}{l}-0.33 \\
(0.69)\end{array}$ \\
\hline \multicolumn{5}{|l|}{ Covariates } \\
\hline Child's age & $\begin{array}{c}8.48 \\
(3.67)\end{array}$ & $\begin{array}{c}8.68 \\
(3.68)\end{array}$ & $\begin{array}{c}8.58 \\
(3.67)\end{array}$ & $\begin{array}{c}7.59 \\
(3.47)\end{array}$ \\
\hline PCG is male & 15.53 & 13.72 & 13.63 & 24.52 \\
\hline \multicolumn{5}{|l|}{ PCG's highest education } \\
\hline Less than middle school & 53.29 & 46.73 & 49.86 & 82.95 \\
\hline Middle school & 35.34 & 39.67 & 41.26 & 12.74 \\
\hline High school and above & 11.37 & 13.60 & 8.88 & 4.32 \\
\hline \multicolumn{5}{|l|}{ Number of siblings } \\
\hline 0 & 28.43 & 29.87 & 18.62 & 30.77 \\
\hline 1 & 50.26 & 49.53 & 55.87 & 48.56 \\
\hline 2 or more & 21.31 & 20.60 & 25.50 & 20.67 \\
\hline Child is from a minority & 11.36 & 12.02 & 10.51 & 8.65 \\
\hline $\begin{array}{l}\text { Family income per capita } \\
\text { (logged) }\end{array}$ & 8.70 & 8.65 & 8.84 & 8.77 \\
\hline & $(0.94)$ & $(1.01)$ & $(0.78)$ & $(0.73)$ \\
\hline \multicolumn{5}{|l|}{ Region } \\
\hline North/Northeast & 13.34 & 16.77 & 7.67 & 2.88 \\
\hline East & 31.50 & 34.19 & 24.72 & 26.20 \\
\hline South-Central & 31.70 & 30.38 & 36.93 & 32.69 \\
\hline West & 23.66 & 18.65 & 30.68 & 38.22 \\
\hline$N$ & 2,473 & 1,705 & 352 & 416 \\
\hline
\end{tabular}


Table 2. Mediation model results: total, indirect, and direct effects.

\begin{tabular}{|c|c|c|}
\hline & $\begin{array}{l}\text { Children left behind by both } \\
\text { parents vs. non-migrant } \\
\text { children }\end{array}$ & $\begin{array}{l}\text { Children left behind by one } \\
\text { parent vs. non-migrant } \\
\text { children }\end{array}$ \\
\hline \multirow[t]{2}{*}{ Total Effects } & $-0.06 * *$ & -0.01 \\
\hline & $(0.02)$ & $(0.02)$ \\
\hline \multirow[t]{2}{*}{ Total Indirect Effects } & $-0.11 * * *$ & 0.04 \\
\hline & $(0.03)$ & $(0.03)$ \\
\hline \multirow[t]{2}{*}{ Remittances (logged) } & -0.02 & $0.07 * *$ \\
\hline & $(0.03)$ & $(0.03)$ \\
\hline \multirow[t]{2}{*}{ Less attentive parenting } & $-0.01 *$ & 0.000 \\
\hline & $(0.003)$ & $(0.001)$ \\
\hline \multirow[t]{2}{*}{ PCG in poor health } & $-0.08 * * *$ & $-0.03 * *$ \\
\hline & $(0.01)$ & $(0.01)$ \\
\hline \multirow[t]{2}{*}{ Remittances through Protein } & -0.002 & $-0.01 * *$ \\
\hline & $(0.0013)$ & $(0.003)$ \\
\hline \multicolumn{3}{|l|}{ Less attentive parenting through } \\
\hline \multirow[t]{2}{*}{ Protein } & $-0.001 *$ & 0.000 \\
\hline & $(0.0005)$ & $(0.000)$ \\
\hline \multirow[t]{2}{*}{ PCG's poor health through Protein } & $-0.0015^{*}$ & 0.000 \\
\hline & $(-0.0006)$ & $(0.000)$ \\
\hline \multirow[t]{2}{*}{ Direct Effects } & 0.05 & -0.05 \\
\hline & $(0.03)$ & $(0.04)$ \\
\hline
\end{tabular}

Notes: standard error in parenthesis

$* * * p$-value $<0.001, * * p$-value $<0.01, * p$-value $<0.05$ 
Table 3. Standardized coefficients for each equation, children left behind by both parents contrasted with children of non-migrant parents.

\begin{tabular}{|c|c|c|c|}
\hline Variables & Coefficient & \multicolumn{2}{|c|}{ p-value } \\
\hline \multicolumn{4}{|l|}{ Child health ON } \\
\hline Less attentive parenting & -0.05 & 0.02 & 0.02 \\
\hline PCG in poor health & -0.34 & 0.02 & 0.00 \\
\hline Logged remittance & -0.02 & 0.03 & 0.48 \\
\hline Protein intake & 0.07 & 0.02 & 0.00 \\
\hline Left behind by both parents & 0.05 & 0.03 & 0.15 \\
\hline Child is male & 0.03 & 0.02 & 0.12 \\
\hline Child's age & 0.21 & 0.11 & 0.06 \\
\hline Childs age squared & -0.14 & 0.11 & 0.20 \\
\hline PCG is male & 0.00 & 0.02 & 0.94 \\
\hline PCG's education: middle school degree & -0.08 & 0.02 & 0.00 \\
\hline PCG's education: high school degree and above & -0.02 & 0.02 & 0.40 \\
\hline Number of siblings: 1 & -0.03 & 0.02 & 0.23 \\
\hline Number of siblings: 2 and above & 0.02 & 0.03 & 0.51 \\
\hline Child is from a minority & 0.01 & 0.02 & 0.67 \\
\hline Logged income per capita & 0.07 & 0.02 & 0.00 \\
\hline Region: East & -0.14 & 0.03 & 0.00 \\
\hline Region: South-Central & -0.19 & 0.03 & 0.00 \\
\hline Region: West & -0.14 & 0.03 & 0.00 \\
\hline \multicolumn{4}{|l|}{ Protein ON } \\
\hline PCG in poor health & -0.09 & 0.02 & 0.00 \\
\hline Less attentive parenting & -0.18 & 0.02 & 0.00 \\
\hline Logged remittance & -0.05 & 0.02 & 0.03 \\
\hline
\end{tabular}




\begin{tabular}{|c|c|c|c|}
\hline Child is male & 0.01 & 0.02 & 0.77 \\
\hline Childs age & -0.14 & 0.11 & 0.19 \\
\hline Childs age squared & 0.17 & 0.11 & 0.10 \\
\hline PCG is male & 0.02 & 0.02 & 0.40 \\
\hline PCG's education: middle school degree & 0.06 & 0.02 & 0.00 \\
\hline PCG's education: high school degree and above & 0.10 & 0.02 & 0.00 \\
\hline Number of siblings: 1 & -0.08 & 0.02 & 0.00 \\
\hline Number of siblings: 2 and above & -0.10 & 0.03 & 0.00 \\
\hline Child is from a minority & -0.02 & 0.02 & 0.36 \\
\hline Logged income per capita & 0.15 & 0.02 & 0.00 \\
\hline Region: East & 0.18 & 0.03 & 0.00 \\
\hline Region: South-Central & 0.13 & 0.03 & 0.00 \\
\hline Region: West & -0.07 & 0.03 & 0.02 \\
\hline \multicolumn{4}{|l|}{ PCG's poor health ON } \\
\hline Left behind by both parents & 0.24 & 0.02 & 0.00 \\
\hline Child is male & 0.02 & 0.02 & 0.47 \\
\hline Childs age & -0.06 & 0.11 & 0.58 \\
\hline Childs age squared & 0.06 & 0.11 & 0.58 \\
\hline PCG is male & -0.02 & 0.02 & 0.29 \\
\hline PCG's education: middle school degree & -0.06 & 0.02 & 0.01 \\
\hline PCG's education: high school degree and above & -0.06 & 0.02 & 0.01 \\
\hline Number of siblings: 1 & 0.05 & 0.02 & 0.05 \\
\hline Number of siblings: 2 and above & 0.07 & 0.03 & 0.01 \\
\hline Child is from a minority & 0.03 & 0.02 & 0.12 \\
\hline Logged income per capita & -0.11 & 0.02 & 0.00 \\
\hline Region: East & 0.10 & 0.03 & 0.00 \\
\hline
\end{tabular}




\begin{tabular}{|c|c|c|c|}
\hline Region: South-Central & 0.21 & 0.03 & 0.00 \\
\hline Region: West & 0.21 & 0.03 & 0.00 \\
\hline \multicolumn{4}{|l|}{ Logged remittances ON } \\
\hline Left behind by both parents & 0.78 & 0.01 & 0.00 \\
\hline Child is male & -0.01 & 0.01 & 0.73 \\
\hline Childs age & -0.03 & 0.07 & 0.69 \\
\hline Childs age squared & 0.02 & 0.07 & 0.76 \\
\hline PCG is male & 0.00 & 0.01 & 0.84 \\
\hline PCG's education: middle school degree & -0.03 & 0.02 & 0.03 \\
\hline PCG's education: high school degree and above & -0.02 & 0.02 & 0.17 \\
\hline Number of siblings: 1 & -0.01 & 0.02 & 0.74 \\
\hline Number of siblings: 2 and above & -0.02 & 0.02 & 0.36 \\
\hline Child is from a minority & 0.00 & 0.01 & 0.98 \\
\hline Logged income per capita & 0.05 & 0.02 & 0.00 \\
\hline Region: East & 0.01 & 0.02 & 0.60 \\
\hline Region: South-Central & 0.01 & 0.02 & 0.53 \\
\hline Region: West & 0.03 & 0.02 & 0.20 \\
\hline \multicolumn{4}{|l|}{ Less attentive parenting $\mathrm{ON}$} \\
\hline Left behind by both parents & 0.10 & 0.02 & 0.00 \\
\hline Child is male & 0.02 & 0.02 & 0.42 \\
\hline Childs age & 0.23 & 0.11 & 0.04 \\
\hline Childs age squared & -0.03 & 0.11 & 0.76 \\
\hline PCG is male & 0.08 & 0.02 & 0.00 \\
\hline PCG's education: middle school degree & -0.11 & 0.02 & 0.00 \\
\hline PCG's education: high school degree and above & -0.14 & 0.02 & 0.00 \\
\hline Number of siblings: 1 & 0.10 & 0.02 & 0.00 \\
\hline
\end{tabular}




\begin{tabular}{lccc}
\hline Number of siblings: 2 and above & 0.16 & 0.03 & 0.00 \\
Child is from a minority & 0.00 & 0.02 & 0.93 \\
Logged income per capita & -0.08 & 0.02 & 0.00 \\
Region: East & 0.05 & 0.03 & 0.10 \\
Region: South-Central & 0.02 & 0.03 & 0.45 \\
Region: West & 0.15 & 0.03 & 0.00 \\
\hline
\end{tabular}


Appendix A. Comparing our survey with the 2010 census.

\begin{tabular}{lcc}
\hline & Percentage (Census) & Percentage (our survey, weighted) \\
\hline Age & 18.8 & 18.6 \\
$0-2$ & 25.1 & 27.3 \\
$3-6$ & 11.3 & 12.3 \\
$7-8$ & 24.3 & 22.9 \\
$9-12$ & 20.5 & 19.0 \\
$13-15$ & & \\
Gender & 46.0 & 45.9 \\
Female & 54.0 & 54.1 \\
Male & & \\
Region & 16.9 & 24.7 \\
North/Northeast & 27.4 & 28.1 \\
East & 31.0 & 31.7 \\
South-Central & 24.7 & 2.5 \\
West & & \\
\hline
\end{tabular}


Appendix B. Definition of mediating variables

\begin{tabular}{ll}
\hline Variables & Descriptions \\
\hline Remittances & What is the total amount of remittances sent by the parent in the past year? \\
\hline & $\begin{array}{l}\text { PCG's degree of involvement and warmth towards the child was measured } \\
\text { by summing responses (on a 1-5 scale) to the following questions: How } \\
\text { many times in the last month ("Not in the past month," "1 or } 2 \text { times in the } \\
\text { past month," "About once a week," "Several times a week," "Every day) } \\
\text { have you }\end{array}$ \\
& $\begin{array}{l}\text { a. Spent time with (CHILD) doing one of (his/her) favorite things? } \\
\text { b. Talked with (CHILD) about things interest him/her? }\end{array}$ \\
PCG Parenting & c. Hugged or caressed (CHILD)? \\
& d. Joked or played with (CHILD) ? \\
& e. Told (CHILD) you appreciated something (he/she) did? \\
& f. Talked with (CHILD) about (his/her) relationships, like relationships \\
& with friends? \\
& g. Talked with (CHILD) about current events, like things in the news? \\
& h. Talked with (CHILD) about (his/her) day?
\end{tabular}

How many times did (CHILD) eat the following food in the past week? (never, 1-2 times, 3-5 times, 6-7 times or more)

Protein intake

a. Fresh chicken, pork, beef, or other kinds of meat cooked separately or in dishes and soups?

b. Fish, shrimp or other seafood?

c. Cow's milk or soy milk?

PCG health PCG's self-rated health ( excellent, very good, good, fair, or poor) 